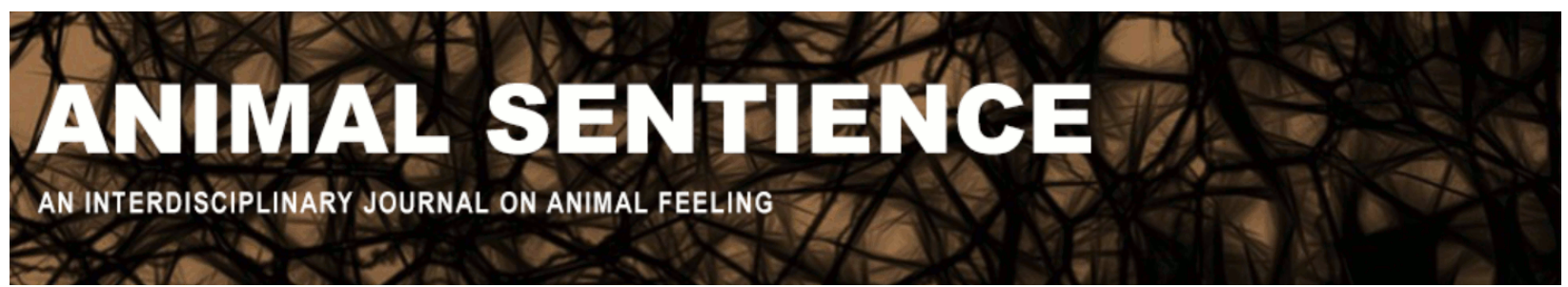

Smith, Travis R. (2017) Establishing that contrast is cognitive dissonance. Animal Sentience 12(9)

DOI: $10.51291 / 2377-7478.1272$

Date of submission: 2017-12-08

Date of acceptance: 2017-12-12

(c)

This article has appeared in the journal Animal

Sentience, a peer-reviewed journal on animal

cognition and feeling. It has been made open access,

free for all, by WellBeing International and deposited

in the WBI Studies Repository. For more information,

please contact

wbisr-info@wellbeingintl.org.

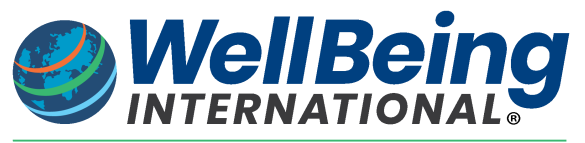

SOLUTIONS FOR PEOPLE, ANIMALS AND ENVIRONMENT 


\title{
Establishing that contrast is cognitive dissonance
}

Commentary on Zentall on Cognitive Dissonance

\author{
Travis R. Smith \\ Language Research Center \\ Georgia State University
}

\begin{abstract}
Zentall suggests that the same mechanism underlies cognitive dissonance in humans and the within-trial contrast effect in pigeons (and humans). The contrast effect has face validity in explaining cognitive dissonance, but more research is needed to establish construct validity. To determine whether both phenomena share the same mechanism, future research should test (1) whether both share physiological processes, (2) whether individuals who show sensitivity to one are also sensitive to the other, and (3) whether both phenomena are affected by the same changes in an independent variable.
\end{abstract}

Travis R. Smith is a postdoctoral associate at the Language Research Center and Georgia State University. He studies risky choice, impulsive choice, and cognitive control in nonhuman animals. mjberan.com/

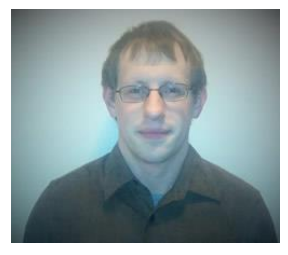

Zentall (2016) proposes that the within-trial contrast effect found in laboratory settings with nonhuman animals ("animals," hereafter) offers a basic mechanism that underlies the observation of cognitive dissonance in research involving humans. On the surface, the phenomena resemble each other in that they both involve some enhanced valuation of a reward that follows an aversive activity (i.e., the animal model has face validity). The question is whether they do so through the same mechanism (i.e., does the animal model have construct validity?). The similarity in the behavioral data between cognitive dissonance in humans and within-trial contrast data in animals is a logical starting point. However, ambitious comparative interpretations of human behavior run the risk of being too generous unless there is a large range of corroborating evidence to support such claims. Zentall's claims about the relationship between within-trial contrast as it relates to cognitive dissonance is an appropriately conservative call for further research on the topic. Below I share ideas on how that might unfold.

A prime example of where animal models have proven fruitful in relating to the psychology of humans is drug addiction research (Peck \& Ranaldi, 2014). In the development of animal models of drug addiction, it is critical that the mechanisms underlying substance abuse in animals are comparable to those underlying human substance abuse disorder. To demonstrate the construct validity of an animal model, it is important to show that humans and animals respond similarly to the same manipulations of the independent variable. Peck \& Ranaldi outlined how animal models showed that drug consumption by animals was affected by the same variables as human drug consumption. For instance, providing environmental enrichment (i.e., non-contingent rewards) has improved drug abstinence in human clinical research (Schottenfeld et al., 2000) as well as in 
animal experimental research (Carroll, Lac, \& Nygaard, 1989). Counterconditioning (i.e., changing a pre-established association between a stimulus and an event) to associate a reward-paired cue with an aversive outcome has also been used in both human (Van Gucht et al., 2010) and animal experimental research (Tunstall, Verendeev, \& Kearns, 2012) to reduce cue-elicited consumption. Human and animal mechanisms may also share homologous physiological substrates. Dopaminergic striatal regions in the brains of rats, monkeys, and humans are all involved in drugseeking behavior (Volkow \& Morales, 2015). The correspondence of behavioral and physiological data in human and animal research has allowed researchers to apply animal models to study ways to improve drug abstinence in humans.

The question remains whether Zentall's (2016) hypothesis - that within-trial contrast accounts more parsimoniously accounts for (or is at least partially involved in) cognitive dissonance - has construct validity beyond face validity. It may be too early to say, but the suggestion is interesting and worthy of further exploration. Along with Vonk (2017), I would like to suggest new research directions that could better support such a claim.

First, any manipulation of a physiological mechanism that affects both within-trial contrast and cognitive dissonance would go far to demonstrate that the two are related. Activation of the dorsal anterior cingulate cortex, implicated in cognitive conflicts such as the Stroop task (Carter \& van Veen, 2007), predicts the degree to which participants' judgments of experiencing (an aversive) fMRI procedure were positive. (Degree of activation predicts the degree of participant "justification" for enduring the event.) This suggests that this brain region is implicated in cognitive dissonance (van Veen, Krug, Schooler, \& Carter, 2009). Since the anterior cingulate cortex is prominently involved in cognitive dissonance and cognitive conflicts, it should also be involved in the within-trial contrast effects found in humans (Klein, Bhatt, \& Zentall, 2005) if they are governed by the same process.

Another way to determine whether cognitive dissonance and the within-trial contrast effect have the same underlying mechanism is to test whether humans who show more predisposition toward cognitive dissonance also tend to be sensitive to the within-trial effect. Zentall \& Stagner's (2011) example is the use of the risky choice paradigm in pigeons as a model of human gambling. Molet et al. (2012) demonstrated that human performance on a risky choice task that included conditioned reinforcers was predictive of gambling habits.

Finally, the conditions that enhance or attenuate within-trial contrast should also affect cognitive dissonance. As noted by other commentators (E. Harmon-Jones, 2017; C. Harmon-Jones et al., 2017) and Zentall (2017) himself, there are already some limitations in equating cognitive dissonance with the contrast effect, such as the fact that humans fail to show cognitive dissonance (despite the presence of the contrast) when they are given instructions that dissociate the aversive event from the value accorded to an experience. Language capacities can change the environment for humans in ways that are not possible for pigeons; however, this does not preclude the possibility that a contrast effect still plays a role in some cognitive dissonance. There could still be nonlinguistic manipulations that reduce/increase the degree of cognitive dissonance in humans and also reduce/increase the degree of within-trial contrast in pigeons: If the degree of task aversiveness were increased parametrically, would the outcome valuation grow continuously, sigmoidally, bitonically (inverse-U shaped), or according to some other function? Would such a function be the same for cognitive dissonance and within-trial contrast? 
Animal research has helped refine theories about the basic mechanisms of human decision-making from an evolutionary perspective (Kalenscher \& van Wingerden, 2011). It is worth exploring the suggestion that the mechanism of cognitive dissonance is similar to the mechanism that affects within-trial contrast. However, the transition from face validity to construct validity will require future research to identify the degree to which the two phenomena correlate and share causal connections with a range of independent variables.

\section{References}

Carroll, M. E., Lac, S. T., \& Nygaard, S. L. (1989). A concurrently available nondrug reinforcer prevents the acquisition or decreases the maintenance of cocaine-reinforced behavior. Psychopharmacology, 97, 23-29.

Carter, C. S., \& Van Veen, V. (2007). Anterior cingulate cortex and conflict detection: An update of theory and data. Cognitive, Affective, \& Behavioral Neuroscience, 7, 367-379.

Harmon-Jones, C., Haslam, N., \& Bastian, B. (2017). Dissonance reduction in nonhuman animals: Implications for cognitive dissonance theory. Animal Sentience 12(4).

Harmon-Jones, E. (2017). Clarifying concepts in cognitive dissonance theory. Animal Sentience 12(5).

Kalenscher, T., \& Van Wingerden, M. (2011). Why we should use animals to study economic decision making-a perspective. Frontiers in Neuroscience, 5, 82.

Klein, E. D., Bhatt, R. S., \& Zentall, T. R. (2005). Contrast and the justification of effort. Psychonomic Bulletin \& Review, 12, 335-339.

Molet, M., Miller, H. C., Laude, J. R., Kirk, C., Manning, B., \& Zentall, T. R. (2012). Decision making by humans in a behavioral task: Do humans, like pigeons, show suboptimal choice? Learning \& Behavior, 40, 439-447.

Peck, J. A., \& Ranaldi, R. (2014). Drug abstinence: Exploring animal models and behavioral treatment strategies. Psychopharmacology, 231, 2045-2058.

Schottenfeld, R. S., Pantalon, M. V., Chawarski, M. C., \& Pakes, J. (2000). Community reinforcement approach for combined opioid and cocaine dependence: Patterns of engagement in alternate activities. Journal of Substance Abuse Treatment, 18, 255-261.

Tunstall, B. J., Verendeev, A., \& Kearns, D. N. (2012). A comparison of therapies for the treatment of drug cues: Counterconditioning vs. extinction in male rats. Experimental and Clinical Psychopharmacology, 20, 447-453.

Van Veen, V., Krug, M. K., Schooler, J. W., \& Carter, C. S. (2009). Neural activity predicts attitude change in cognitive dissonance. Nature Neuroscience, 12, 1469-1474.

Vonk, J. (2017). What can research on nonhumans tell us about human dissonance? Animal Sentience $12(2)$.

Zentall, T. R. (2016). Cognitive dissonance or contrast? Animal Sentience 12(1).

Zentall, T. R., \& Stagner, J. (2011). Maladaptive choice behaviour by pigeons: An animal analogue and possible mechanism for gambling (sub-optimal human decision-making behaviour). Proceedings of the Royal Society of London B: Biological Sciences, 278, $1203-$ 1208. 